\title{
APLICAÇÃO DA ESCALA TEMPORO-ESPACIAL FINA EM ESTUDO DE INUNDAÇÕES URBANAS: PAINÉIS PARA CURITIBA-PR, BRASIL
}

\author{
APLLICATION OF FINE SPATIAL-TEMPORAL SCALE TO THE URBAN FLOODING: PANELS TO CURITIBA-PR, \\ BRAZIL
}

\author{
Francisco de Assis Mendonça' ${ }^{1}$ Elaiz Aparecida Mensch Buffon ${ }^{1}$ \\ ${ }^{1}$ Universidade Federal do Paraná (UFPA), Curitiba, PR, Brasil
}

Correspondência para: Francisco de Assis Mendonça (chico@ufpr.br)

doi: 10.12957/geouerj.2019.40943

Recebido em: 15 ago. 2018 | Aceito em: 01 nov. 2018

\section{RESUMO}

Os eventos climáticos extremos associados às chuvas e inundaç̃̃es estão no centro da analise desenvolvida no presente texto. A variabilidade espaço-temporal da precipitação, associada à configuração de dois eventos hidrometeorológicos extremos/inundações na Cidade de Curitiba-PR, constitui dois estudos de caso utilizados como exemplo. Os episódios selecionados são decorrentes da atuação da MTa (Verão) e outro da FF (Outono). Utilizou-se de dados de no mínimo 40 pluviômetros automáticos e de dados climáticos gerais registrados em estações automáticas na escala horária. Os dados foram fornecidos pelo Centro Nacional de Monitoramento e Alertas de Desastres Naturais (CEMADEN) e pelo Instituto Tecnológico SIMEPAR (Sistema Meteorológico do Paraná). A metodologia empregada apoia-se na estatística e no sistema de informação geográfica para representação espaço-temporal, com destaque para a criação de painéis. Os resultados, para Curitiba e seu aglomerado, demonstram que: 1 ) as inundações são decorrentes de eventos extremos de chuva, que ocorrem em curto intervalo de tempo (horas) e são localizados espacialmente em decorrência da dinâmica climática; 2) os eventos extremos de chuva, decorrentes da atuação da FF, avançam do sul para o centro-oeste e centro-leste da área, enquanto que a atuação da MTa configura um avanço de leste para norte, que se desloca para o oeste e sudoeste. A configuração espaço-temporal da precipitação pluvial em episódios de inundações evidencia a importância do emprego da analise em escala fina (horária e minutos) com uma densa distribuição de estações.

Palavras-chave: Sistemas atmosféricos. dinâmica climática. analise espacial. escala fina. Curitiba.

\begin{abstract}
The extreme climatic events associated with rains and floods are at the center of the analysis developed in this text. The spatial-temporal variability of precipitation, coupled with the configuration of two extreme hydrometeorological events / floods in the city of Curitiba-PR, constitutes two case studies used as examples. The selected episodes are due to the performance of MTa (Summer) and FF (Autumn). Data of at least 40 rain automatic and of general climatic data recorded in automatic stations on the hourly scale were used. The data were provided by the National Center for Natural Disaster Monitoring and Alarms (CEMADEN) and the SIMEPAR Technological Institute (Paraná Meteorological System). The methodology employed is based on statistics and the geographic information system for space-time representation, with emphasis on the creation of panels. The results, for Curitiba and its cluster, show that: 1) floods are due to extreme rainfall events, which occur in a short time (hours) and are localized spatially due to the climatic dynamics; 2) extreme rain events, due to FF performance, advance from the south to the center-west and center-east of the area, while the MTa performance represents an advance from east to north, which moves westward and south-west. The spatiotemporal configuration of rainfall in flood episodes shows the importance of the use of fine scale analysis (hourly and minutes) with a dense distribution of seasons.
\end{abstract}

Keywords: Atmospheric Systems. Climatic Dynamics. Spatial Analysis. Fine Scale. Curitiba.

\section{INTRODUÇÃO}


As inundações urbanas são fenômenos com importantes impactos negativos no cotidiano das sociedades em muitas partes do mundo. No que se refere a sociedade brasileira, a elevação do número de ocorrências nas últimas décadas (1990 a 2015) (AMARAL E RIBEIRO, 2009). Corroborando com as afirmações acima Mendonça (2013) aponta que as inundações têm promovido impactos negativos e recorrentes para a sociedade no estado do Paraná, o que amplia a importância da gestão de desastres associados às inundações urbanas.

Uma das grandes dificuldades que ainda permeia a gestão de desastres, consiste nas ações das fases de prevenção e preparação da gestão de risco de desastres. Gregório et al. (2015) cita que o tema de gestão de desastres no Brasil é recente, e ainda mais nova a prática de gestão de risco de desastres, ou seja, por muitos anos as ações eram voltadas exclusivamente para respostas. Nesse sentido, avançar na gestão de riscos de desastres significa caminhar para uma minimização e/ou erradicação do problema das inundações em áreas urbanas, reduzindo os desastres e possibilitando melhores condições de vida para as populações (CUNHA, 2007; BOTELHO, 2011).

Propor uma gestão integral de riscos de desastres significa adotar uma visão sistêmica do problema (GREGORIO et al., 2015). Para isso torna-se necessário inter-relacionar processos que ocorrem no âmbito da atmosfera, litosfera, hidrosfera e biosfera, considerando como output desses processos os impactos socioambientais a eles associados. No cenário atual, mesmo que com avanços significativos provenientes da revolução tecnológica, a análise integrada de parâmetros físicos, sociais e ambientais é limitada, principalmente, em relação aos dados e suas respectivas escalas disponíveis para o território brasileiro, que nem sempre permitem integração.

A gestão do risco de inundações, por exemplo, carece de estudos da gênese das inundações que precisa de dados de pluviosidade. A maior gama existente dos dados de chuva consiste em registros diários, coletados em estações convencionais da Agência Nacional de Águas. É recente a instalação de estações automáticas do Instituto Nacional de Meteorologia (INMET) e pluviômetros automáticos do Centro Nacional de Monitoramento e Alertas de Desastres Naturais (CEMADEN), com registros, respectivamente, horário e de 10 em 10 minutos. Outro problema associado é a distribuição espacial 
dessas estações e pluviômetros automáticos que, em sua grande maioria, são restritos para algumas áreas mapeadas como de interesse prioritário, ou, para capitais brasileiras.

Compreender os processos atuantes na atmosfera, especialmente aqueles inseridos num sistema de clima urbano, é uma atividade complexa. Para superar essa complexidade, que se conforma tanto na dimensão do tempo quanto do espaço, torna-se imprescindível análises na escala de detalhe (menor nível de desagregação) possível, alimentando assim, estudos da microclimatologia.

Assim, compreende-se que o estudo da variabilidade climática é a variação "no interior de um determinado período de registros expressos através de desvio-padrão ou coeficiente de variação" (CONTI, 2000, p.20), e que se mostra como relevante para o entendimento dos processos atuantes na atmosfera. Compreender a gênese e configuração espaço-temporal da precipitação é aspecto primordial, por exemplo, para a criação de alertas de eventos extremos.

O conhecimento da gênese da precipitação envolve, necessariamente, uma abordagem qualitativa e quantitativa, associada a interpretação dos sistemas atmosféricos (MONTEIRO, 1971), e a análise estatística dos padrões de precipitação. No que se refere ao entendimento da configuração espaçotemporal da precipitação, torna-se imprescindível uma análise espacial apoiada em técnicas estatísticas e Sistema de Informação Geográfica - SIG (LONGLEY et al., 2013).

Estudos como os de Zanella (2006) e Mendonça et al. (2015) enfatizam análises de inundações a partir da gênese e configuração espaço-temporal da precipitação, utilizando dados diários. No entanto, os eventos de inundações, muitas vezes, não respondem aos totais pluviométricos diários, uma vez que são eventos localizados e de curta duração, com exceção das inundações graduais.

Nesta perspectiva, para compreender a gênese e configuração espaço-temporal das inundações, é fundamental um nível de desagregação de dados de maior detalhe (dados horários e/ou de minutos). Essa desagregação, associada a uma densa distribuição de estações ou pluviômetros, encaminha as análises da climatologia para o uso na dimensão da escala fina. No âmbito da necessidade de maior 
detalhamento Longley et al., (2013, p.166) chamam atenção para o fato de que "boas análises em SIG não podem substituir concepções ou representações geográficas pobres - elas podem sinalizar as prováveis consequências de ambas”.

Na perspectiva da realização de estudos em escala fina apresenta-se este texto que visa, a partir do uso de dados horários, estabelecer análises sobre a configuração espaço-temporal da precipitação para dois episódios de inundações em Curitiba, avaliando a correlação com elementos climáticos. Cabe ressaltar que esses episódios tiveram suas gêneses em sistemas atmosféricos diferentes, o que permite verificar variabilidades espaciais e temporais distintas. Com isso, entende-se que esse trabalho é uma proposta bastante promissora para demonstrar a necessidade de estudos da climatologia na escala fina, ou seja, horária e de minutos.

\section{MÉTODOS E TÉCNICAS}

Os episódios de inundações aqui enfocados foram selecionados com base no levantamento realizado por Mendonça e Buffon (2018). Nesse levantamento os autores analisaram a dinâmica climática associada a 34 episódios de inundações e concluíram que 44,8\% dos episódios são ocasionados durante a atuação da Massa Tropical Atlântica (Mta), e 41,4\% dos episódios são decorrentes de Frente Fria (FF).

Partindo dessa conclusão considerou-se os seguintes critérios para definição de dois episódios de inundações para análise neste trabalho: 1) diferentes sistemas atmosféricos atuantes, 2) dados em escala espaço-temporal fina (registro horária e densa distribuição de estações), 3) valores superiores a $45 \mathrm{~mm} / \mathrm{h}$, e 4) ocorrência em diferentes estações.

Com os dois episódios definidos, 22/02/2016 e 06/06/2017, foi necessário coletar dados para a análise da configuração da precipitação pluvial e sua relação com a direção dos ventos. Assim, foram coletados os dados de precipitação pluvial registrados na cidade de Curitiba e circunvizinhas, através de estações automáticas, do Centro Nacional de Monitoramento e Alertas de Desastres Naturais (CEMADEN) no período de 2016 e 2017, contabilizando um total de 40 estações para os dados de 
2017 e 42 estações para o ano de 2016 (Figura 1). Também, foram coletados dados de velocidade e direção dos ventos para uma estação automática do Sistema Meteorológico do Paraná para o período de 2016 e 2017, disponibilizados pelo SIMEPAR (Figura 1).

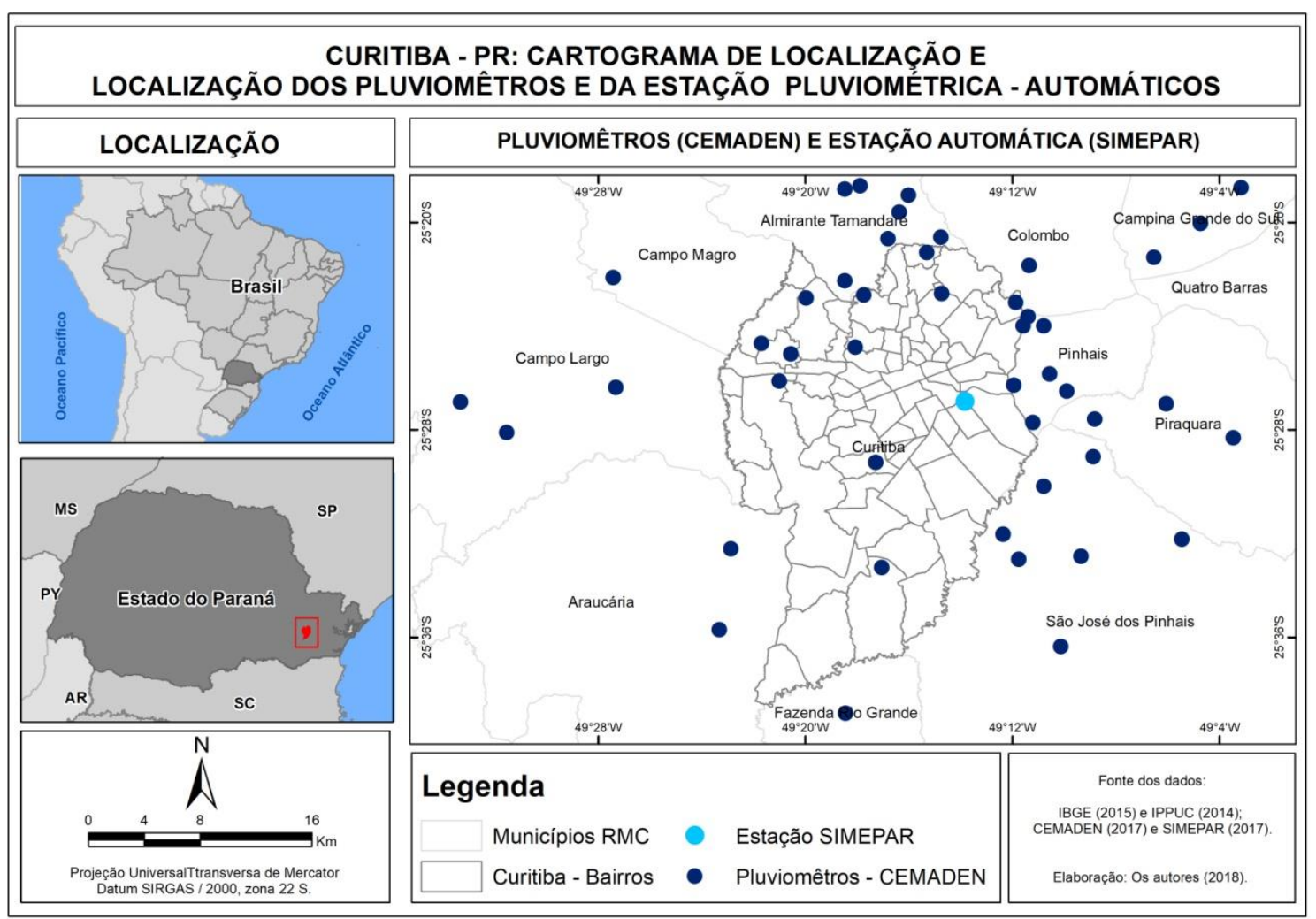

Figura 1. Aglomerado Urbano-metropolitano de Curitiba/PR - Localização da área de estudo, dos pluviômetros e da estação automática. Elaboração: Mendonça e Buffon (2018).

O passo seguinte foi a elaboração de mapeamentos da configuração espacial horária da precipitação pluvial. Os mapeamentos foram elaborados utilizando-se o software ArcGIS Esri 10.3.1, por meio da interpolação dos dados na extensão Geostatistical Analyst, na opção Geostatistical Wizard, a partir do método de Krigagem (ISAAKS \& SRIVASTAVA, 1989). Para obter uma determinação de classes e intervalo com melhor confiabilidade, utilizou-se a regra de Sturges, a saber (Equação 1):

$$
K=1+3,3 \cdot \log n
$$

(Equação 1)

A análise estatística dos dados horários de precipitação pluvial consistiu no cálculo do coeficiente de variação (Equação 2), que é a porcentagem do desvio padrão em relação a sua média. 


$$
C V=\frac{s}{\bar{x}} \cdot 100 \quad \text { (Equação 2) }
$$

Os dados de direção dos ventos foram representados de forma integrada com os dados de precipitação pluvial e velocidade dos ventos. Para essa integração utilizou-se o software WRPLOT View (desenvolvido pelo Lakes Environmental Software - Canadá), que é um programa de operações voltado para retratar estatísticas de direção dos ventos, e que permite integrar dados meteorológicos.

\section{RESULTADOS E DISCUSSÃO}

\section{Caracterização dos episódios de inundações (22/02/2016 e 06/06/2018)}

Mendonça et al. (2013) constata que entre o início e meados do século XX apenas as áreas centrais da cidade de Curitiba destacavam-se por apresentar inundações. Foram nessas áreas, com intuito de minimizar impactos, que o poder público em conjunto com a iniciativa privada atuou na criação de parques, projetos de engenharia hidráulica e sanitária. Como exemplo cita-se o parque Barigui, localizado na porção oeste da cidade, e que visa conter inundações.

As áreas pericentrais e periferias geográficas passaram a registrar episódios de inundações e impactos associados após a metade do século XX. Esses registros estão associados, principalmente, à expansão da cidade nem sempre dotada de infraestrutura que, atrelado aos eventos extremos de chuva, geram áreas e situações de riscos. A este respeito autores como Geissler \& Loch (2004) apontam que as obras de engenharia desconsideraram as reais causas dos problemas e, em muitas vezes, acabam por transferir as consequências para áreas e municípios à jusante da bacia de drenagem.

Estudos como os de Deschamps (2004), Zanella (2006), Fortunato (2006), Cunico (2013), Lohmann (2011), Mendonça et al., (2015), demonstram que as inundações não se distribuem de maneira homogênea em Curitiba e seu aglomerado. Assim, surge uma grande demanda em conhecer a configuração da precipitação pluvial em episódios de inundações, visando auxiliar na criação de 
mecanismos de alerta climático. Essa configuração pode ser analisada em diversas escalas, desde diária, horária e até minutos.

Na figura 2 são apresentados os totais diários de precipitação pluvial para os dois episódios em analise neste texto. Os mapeamentos permitem destacar que o episódio do dia 06 de junho de 2017 caracterizou os maiores totais $(24 \mathrm{~h})$ de precipitação pluvial e, também, abrangeu uma área maior. No que se refere a espacialidade da precipitação, observou-se que no episódio de 06 de junho de 2017, com atuação da Frente Fria (FF), a precipitação pluvial de maior magnitude se concentrou no centroleste e centro-norte de Curitiba, formando um corredor de precipitação pluvial de maior magnitude, que abarcou, principalmente, as cidades de Pinhais e Campo Largo (Figura 2). Por outro lado, o episódio de 22 de fevereiro de 2016, com atuação da Massa Tropical Atlântica, desenvolveu uma concentração da precipitação pluvial na porção norte e oeste de Curitiba, com demarcação importante em Almirante Tamandaré (Figura 2).

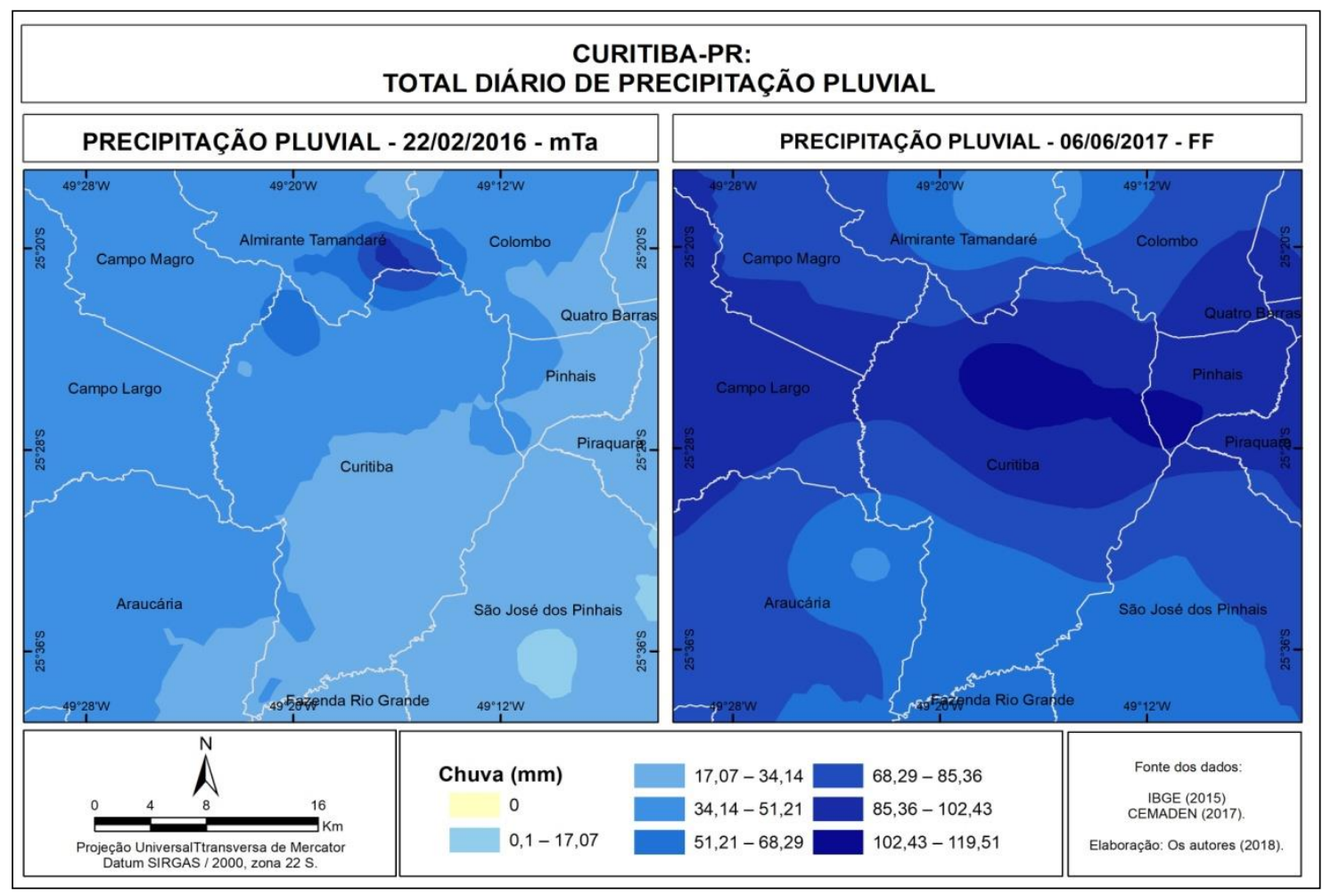

Figura 2. Curitiba/PR - Configuração espacial da precipitação total (24h) em dois episódios de inundações de 22/02/2016 e 06/06/2017. Elaboração: Mendonça e Buffon (2018).

As figuras 3 e 4 ilustram os episódios de inundações a partir de registros fotográficos da imprensa. Na figura 3 apresenta-se ruas inundadas nos bairros Alto da XV e Boa Vista, que ilustram alguns 
impactos decorrentes. A figura 4 retrata ruas e casas inundadas nos bairros Parolin, Padro Velho e Rebouças, e também na Linha Verde de Curitiba. A partir desses registros fotográficos torna-se perceptível que os impactos decorrentes de inundações geram "consequências calamitosas, atacando a integridade da cidade como artefato físico e perturbando, sensivelmente, as formas de circulação e comunicação" (MONTEIRO, 2003, p.53).
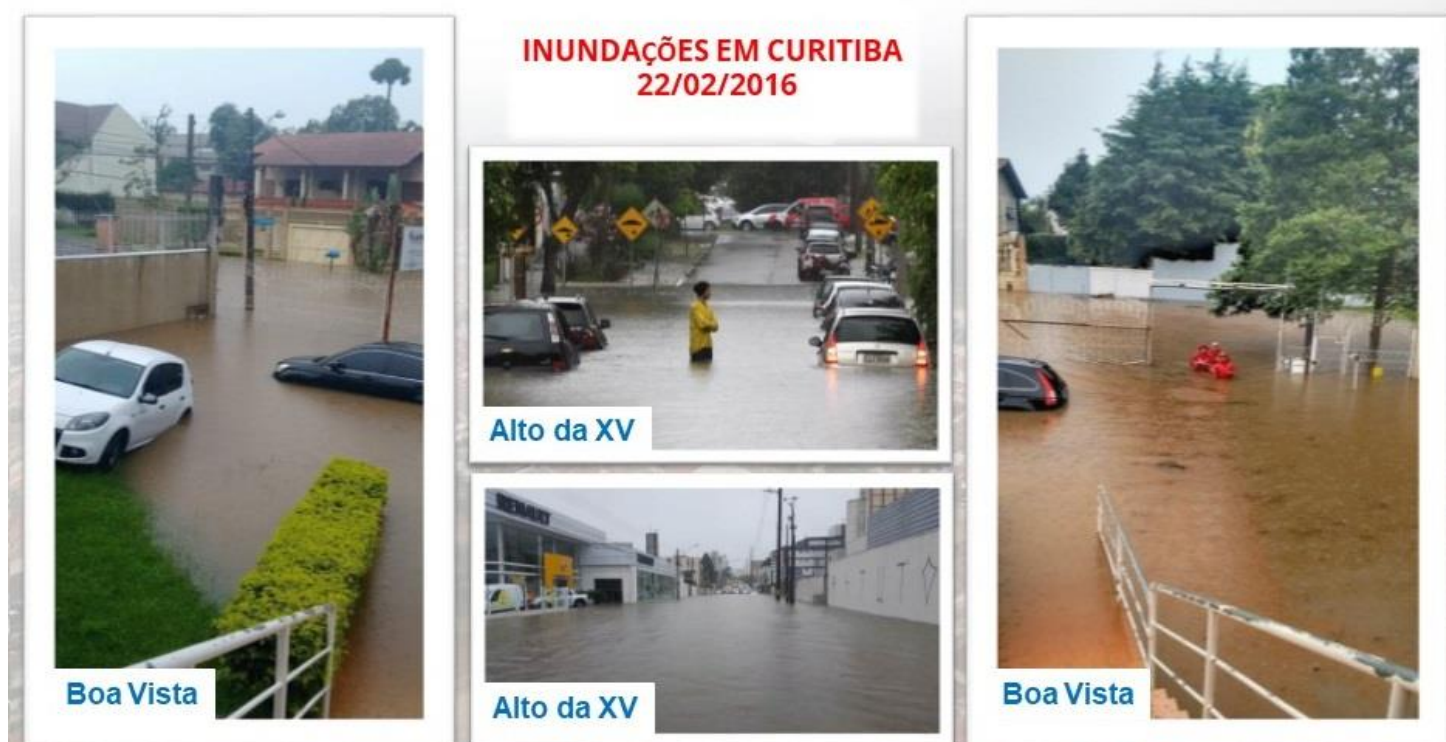

Figura 3. Curitiba-PR: Registros fotográficos da inundação no dia 22 de fevereiro de 2016. Fotos: GAZETA DO POVO e RIC MAIS, 2016. Org.: Mendonça e Buffon (2018).
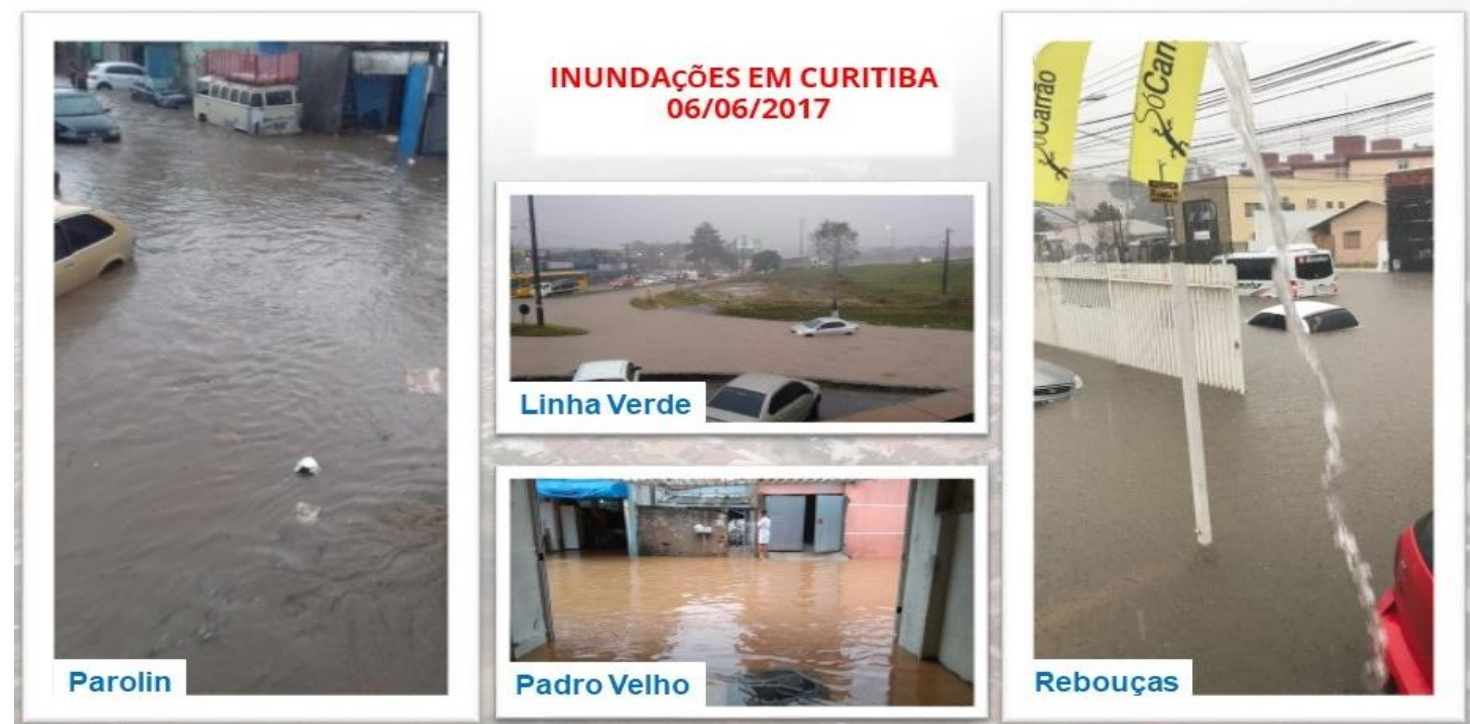

Figura 4. Curitiba-PR: registros fotográficos da inundação no dia 06 de junho de 2017. Fotos: BANDA B (2017). Org.: Mendonça e Buffon (2018).

\section{Episódios de inundações (22/02/2016 e 06/06/2017): configuração dos eventos extremos da precipitação pluvial}


Os episódios de inundações são resultados de eventos extremos de chuva que interagem com a problemática socioambiental dos lugares. É complexa a tarefa de indicar o que é um evento extremo de chuva, pois esse valor varia no espaço e no tempo. Marengo (2009) destaca que os eventos extremos ou excepcionais resultam de condições discrepantes de um estado médio do clima, que varia de curto prazo (tempo) até os de médio prazo (clima), e são geradores de adversidades climáticas.

As inundações podem ser classificadas em brusca ou gradual, no entanto, diversos fatores interferem para o resultado dessa classificação. Um desses fatores é a intensidade da precipitação. Para tanto, faz-se necessário utilizar uma escala temporal fina, ou seja, que represente os pequenos intervalos de tempo de um evento. Assim, é de extrema importância utilizar dados na escala horária ou de minutos, visto que esses permitem identificar a configuração da precipitação de maior magnitude que pode provocar inundações.

Neste contexto, foram elaboradas as figuras 5 e 6 , que constituem painéis tempôro-espaciais da precipitação pluvial nos dois episódios de inundações. Esses painéis apresentam os acumulados horários de precipitação pluvial, possibilitando observar a configuração a priori e a posteriori do interim da inundação.

Na figura 5 observa-se a configuração horária da precipitação pluvial para o episódio de inundação do dia 22 de fevereiro de 2016, que foi decorrente da atuação da Massa Tropical Atlântica (Mta). A configuração é direcionada no sentido leste para norte de Curitiba, que escoa pelo oeste até atingir o sudoeste (Figura 5). A precipitação pluvial de maior magnitude ocorreu das 12 h00 até às 15 h00 na porção norte e escoando para oeste, e entre às $15 \mathrm{~h} 00$ até às $17 \mathrm{~h} 00$ se deslocando para o sudoeste (Figura 5).

O painel do episódio do dia 06 de junho de 2017, com atuação da Frente Fria, apresenta dois períodos de precipitação pluvial de maior magnitude, sendo esses: 1) entre 00h01 até às 02h00, com entrada da precipitação pelo sul-sudoeste, que se desloca até o norte, abrangendo áreas extensas; 2) entre 15 h00 
até às $17 \mathrm{~h} 00$, com destaque para às $16 \mathrm{~h} 00$, com entrada da precipitação pelo sudeste e desloca para nordeste e centro-oeste, abrangendo uma extensa área (Figura 6).

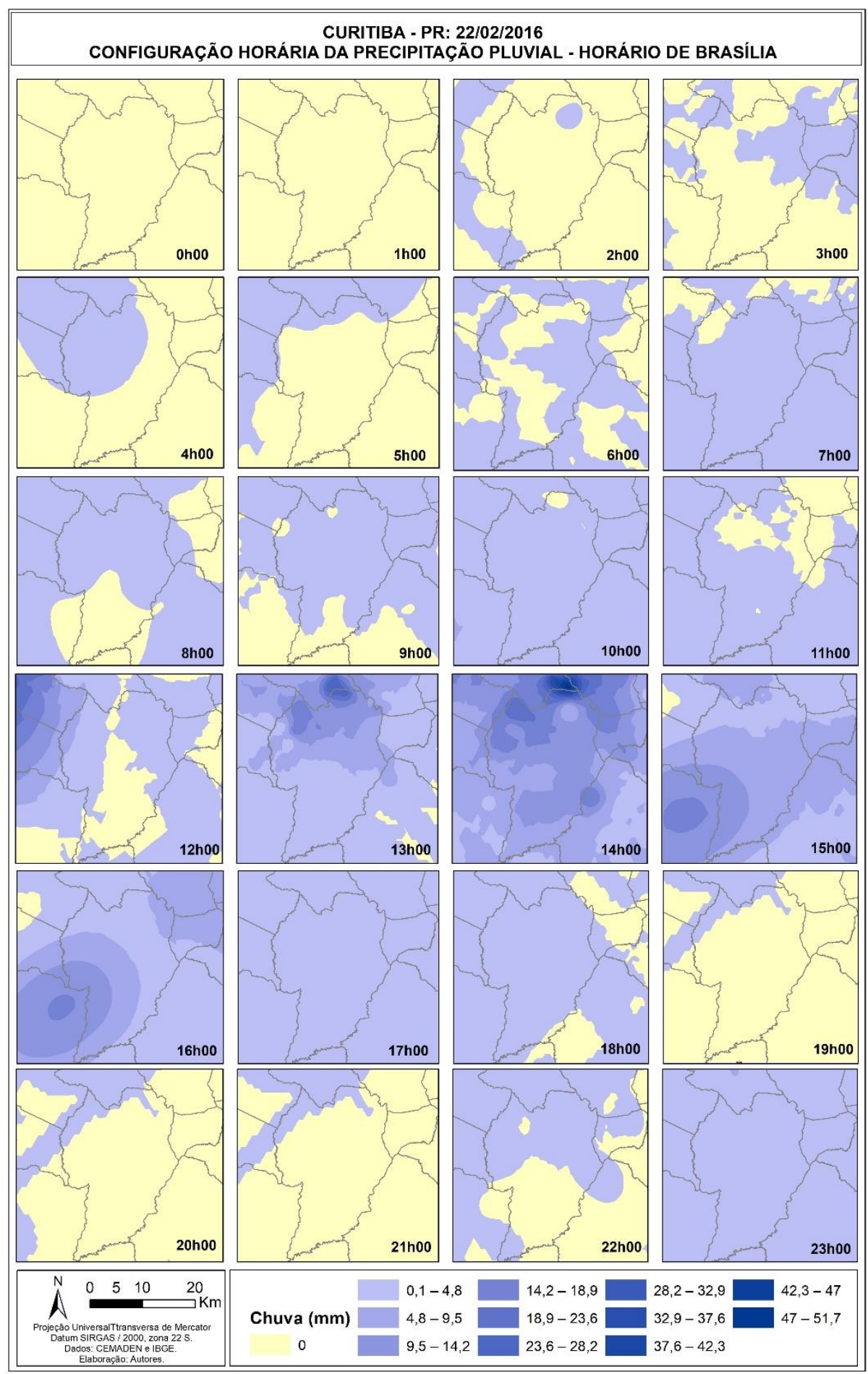

Figura 5. Curitiba-PR: Painel tempôro-espacial da precipitação pluvial no episódio de 22 de fevereiro de 2016. Elaboração: Mendonça e Buffon (2018). 


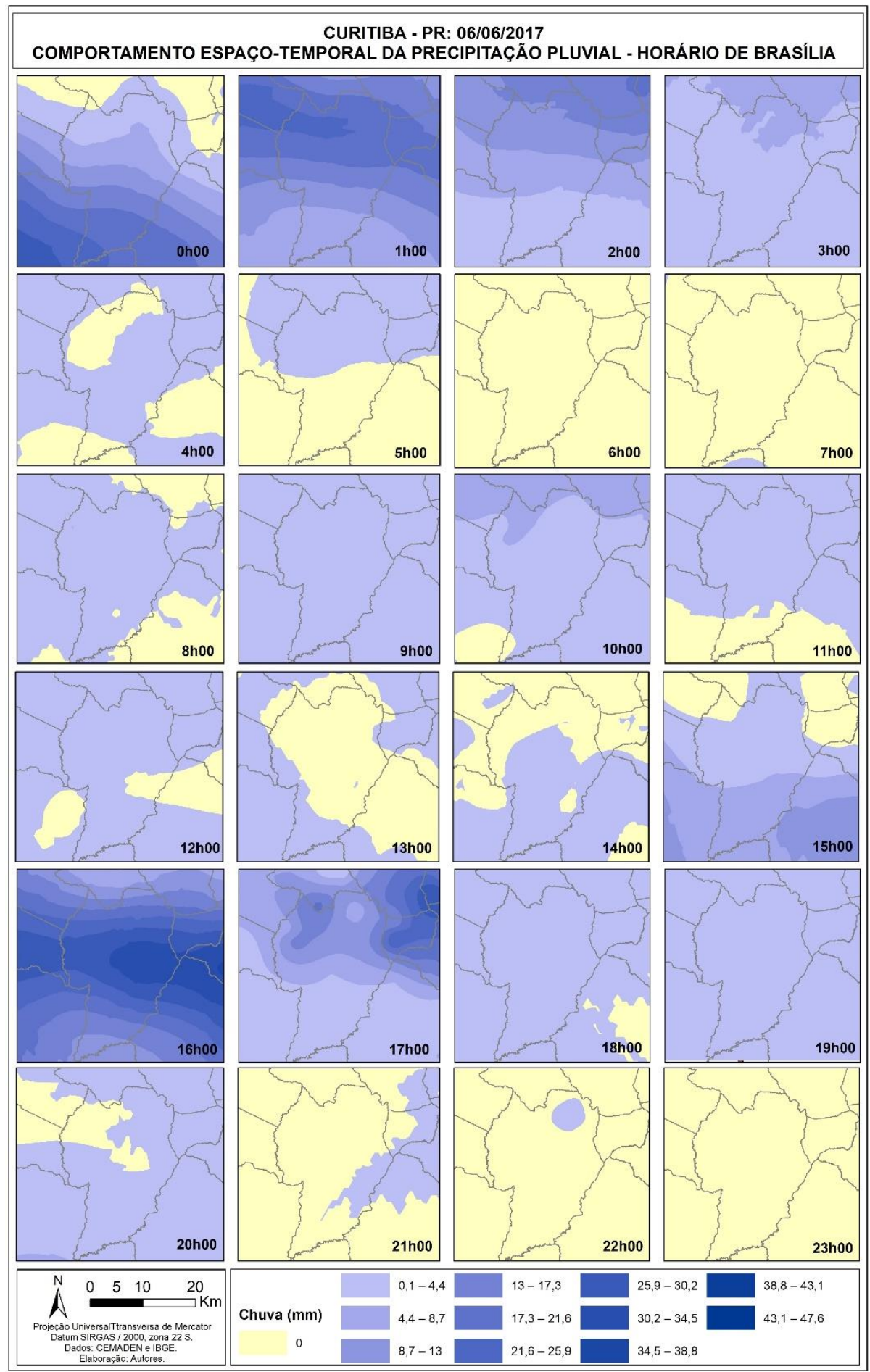

Figura 6. Curitiba-PR: Painel tempôro-espacial da precipitação pluvial no episódio de 06 de junho de 2017. Elaboração: Mendonça e Buffon (2018).

A configuração da precipitação pluvial em um determinado lugar é condicionada por fatores estáticos e dinâmicos. Dentre os fatores dinâmicos destaca-se a movimentação dos sistemas atmosféricos, que são se relacionam diretamente com a direção e velocidade dos ventos. Neste trabalho, são analisados dois episódios de inundações, um atrelado a atuação da Mta (22/02/2016), e outro à FF (06/06/2017). 
A Mta atua durante o ano todo em Curitiba, e apresenta sua gênese no centro de altas pressões subtropicais do Atlântico, caracterizando-se pela temperatura e umidade elevadas, que adentram ao continente e provocam precipitações (MENDONÇA \& DANNI-OLIVEIRA, 2007). A FF ocorre por meio do encontro do ar frio, denso e pesado, com o ar quente, menos denso e mais leve, e apresenta rápido deslocamento pelo continente, provocando grande parcela das chuvas da região Sul do Brasil (MENDONÇA \& DANNI-OLIVEIRA, 2007).

Assim, a figura 7 representa a direção leste dos ventos durante o episódio de 22 de fevereiro de 2016, com exceção das $15 \mathrm{~h} 00$ quando a direção foi nordeste e ocasionou a precipitação mais intensa do dia. A velocidade do vento predominante foi de 1 a $2 \mathrm{~m} / \mathrm{s}$, com exceção da hora em que houve a precipitação mais intensa, momento no qual se registrou vento entre 3 a $4 \mathrm{~m} / \mathrm{s}$. Esses dados corroboram a configuração da precipitação apresentada anteriormente, uma vez que o ar úmido e quente do oceano Atlântico adentra ao continente, no sentindo leste e nordeste de Curitiba devido, sobretudo, à influencia da altitude e da geomorfologia local (Serras do Mar e Escarpa do Devoniano, e direção das grandes bacias de drenagem).

A direção predominante dos ventos durante o episódio de 06 de junho de 2017 foi de oeste e noroeste (figura 8), com exceção das $17 \mathrm{~h} 00$ cuja direção foi de sudoeste, e assim deslocou o elevado volume de precipitação que se concentrava no centro-oeste para o nordeste da cidade. A velocidade do vento, predominante, foi de 2 a $4 \mathrm{~m} / \mathrm{s}$. Essa condição expressa a configuração supracitada da precipitação desse episódio de inundação, que tem sua gênese no sul e se desloca para o centro-oeste e centro-leste da área de estudo. 

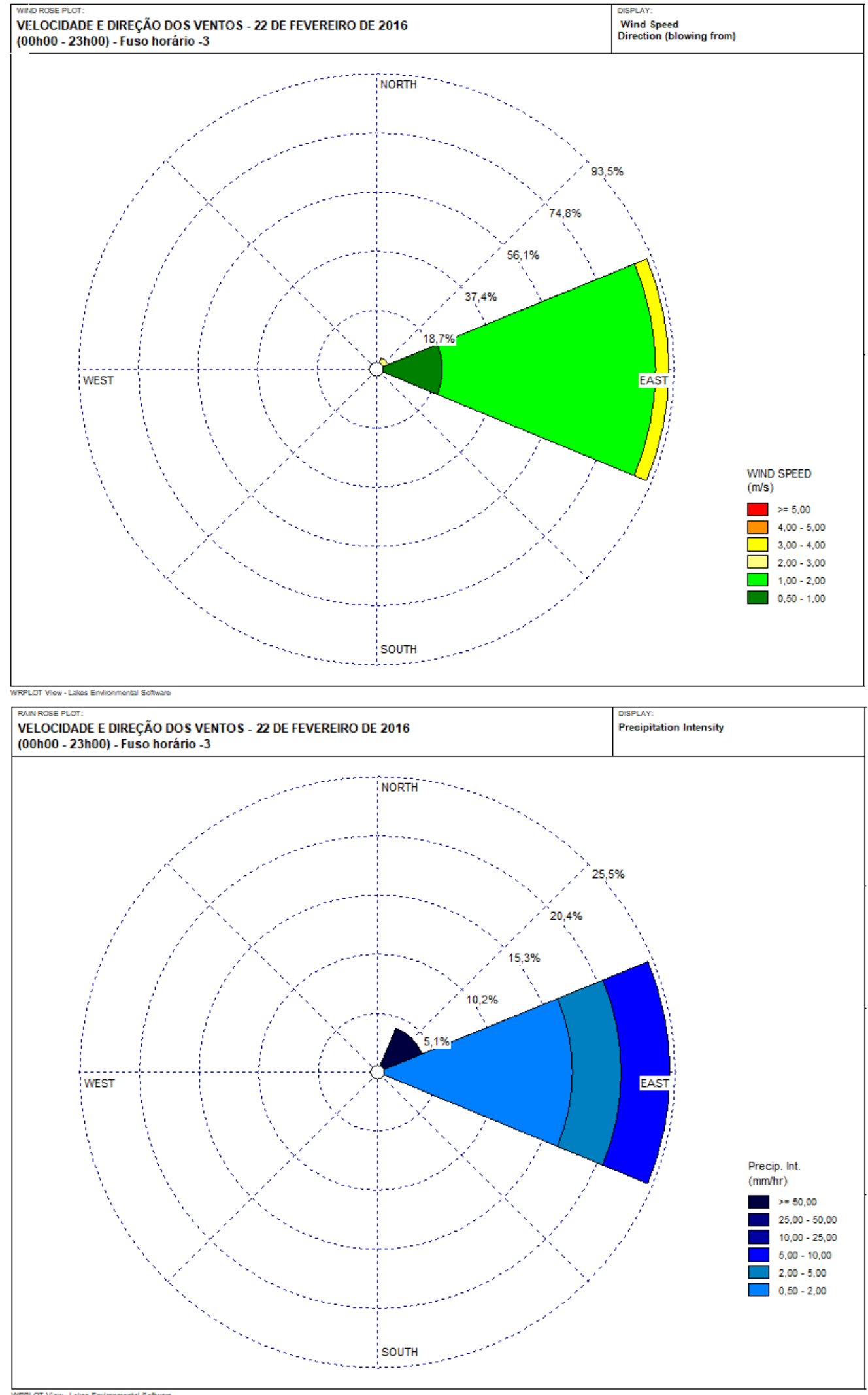

Figura 7. Curitiba (Estação SIMEPAR) - 22/02/2016: Descrição integrada da direção e velocidade dos ventos, com a precipitação pluvial. Elaboração: Mendonça e Buffon (2018). 

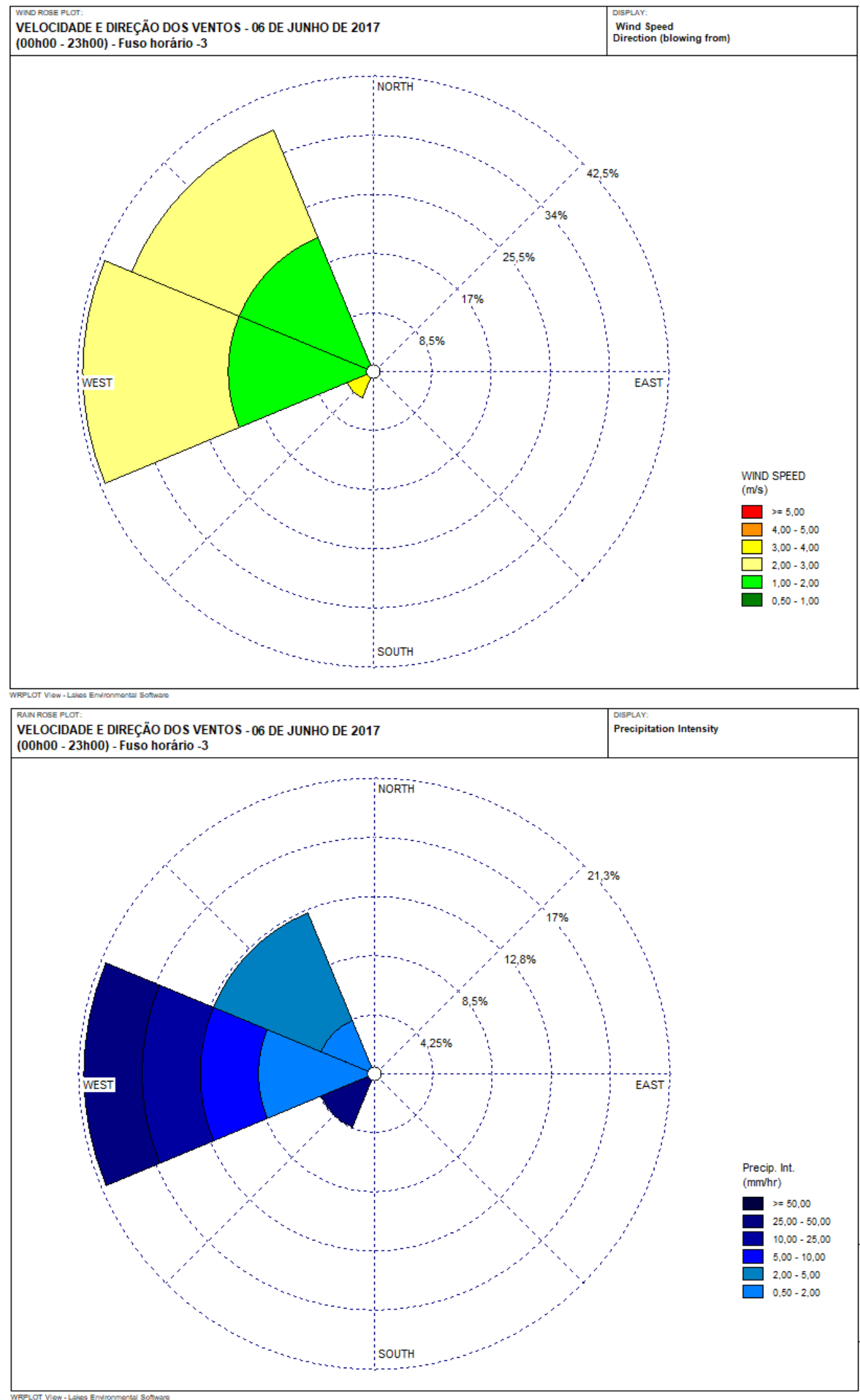

Figura 8. Curitiba (Estação SIMEPAR) - 06/06/2017: Descrição integrada da direção e velocidade dos ventos, com a precipitação pluvial. Elaboração: Mendonça e Buffon (2018). 
A análise da configuração da precipitação, a partir de painéis tempôro-espaciais, na escala horária e com densa distribuição de pluviômetros, permite observar que os eventos extremos de chuva não são homogêneos ao longo de uma cidade. Isso demonstra que utilizar dados de somente uma estação meteorológica, por exemplo, para representar os eventos extremos de chuva e seus episódios de inundações, pode ocasionar incongruências na avaliação.

Com o objetivo de validar essa afirmação elaborou-se as figuras 9 e 10, que representam em gráficos, a partir da estatística, a variação da precipitação, considerando a rede densa de pluviômetros ao longo das 24 horas dos episódios. Ambas as figuras permitem destacar que, durante as horas que marcam as chuvas mais intensas nos episódios de inundações, a variação entre os 40 e 42 pluviômetros alcança valores superiores ao $100 \%$ de variação (Figuras 9 e 10).

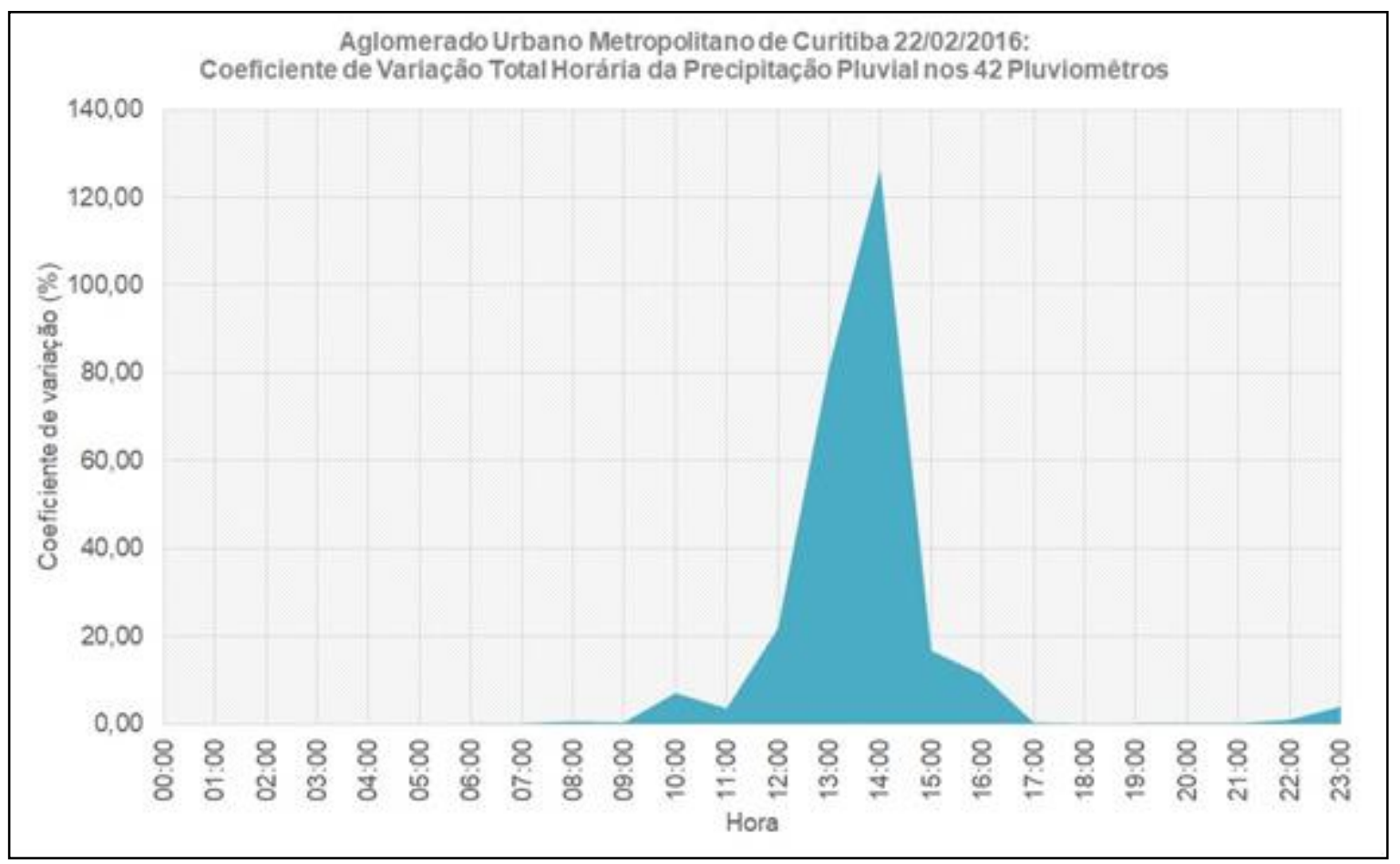

Figura 9. Curitiba/PR - Variação da precipitação pluvial horária registrada nos 42 pluviômetros no episódio de 22 de fevereiro de 2016. Elaboração: Mendonça e Buffon (2018). 


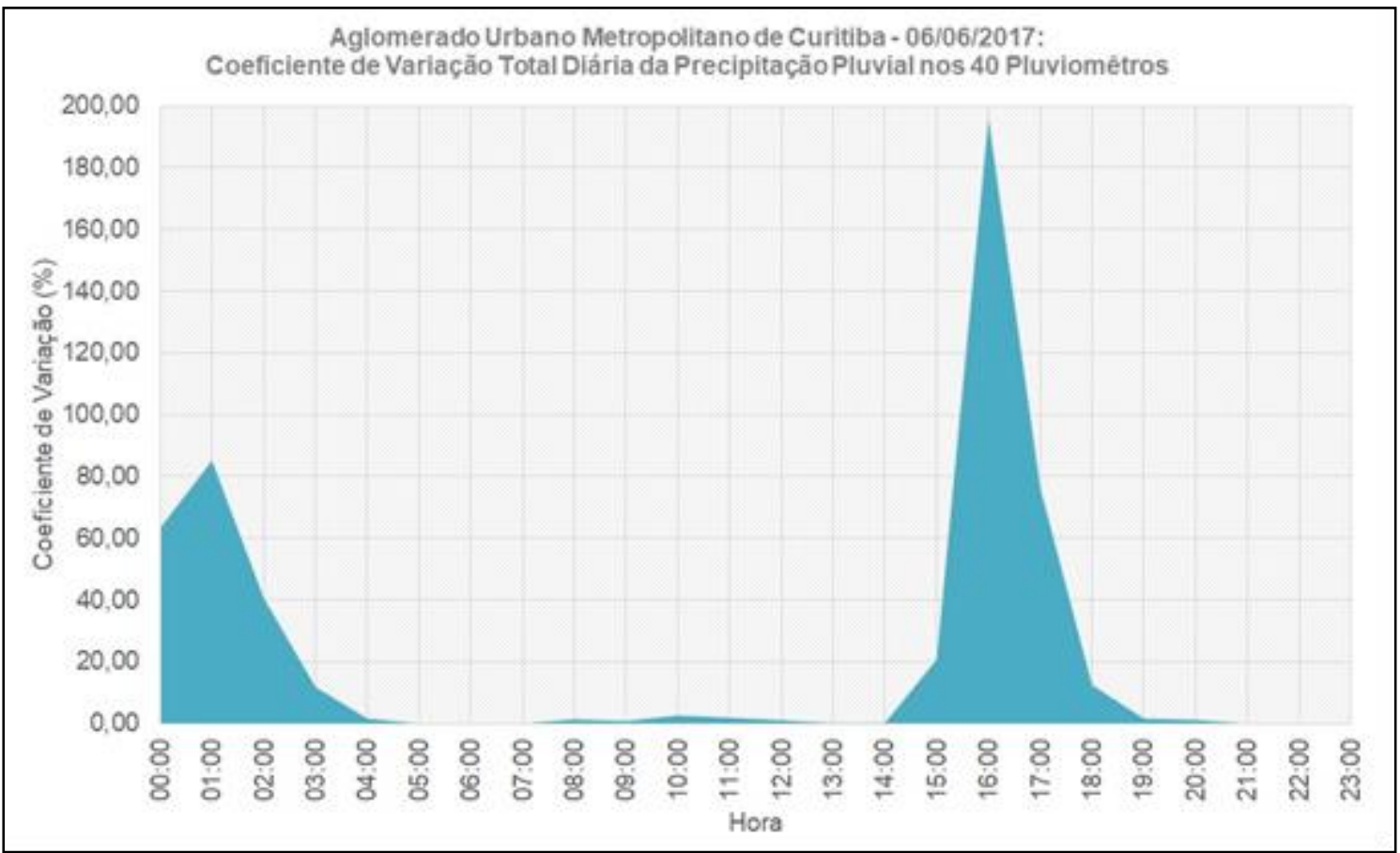

Figura 10. Curitiba/PR - Variação da precipitação pluvial horária registrada nos 40 pluviômetros no episódio de 06 de junho de 2017 em Curitiba/PR. Elaboração: Mendonça e Buffon (2018).

Nesse sentido fica evidente que a aplicação de uma escala temporal fina para análise das precipitações que ocasionam inundações é de extrema importância. Essa escala fina deve comtemplar tanto um intervalo temporal de horas quanto de minutos, bem como uma densa distribuição de pluviômetros. A aplicação da escala fina possibilita identificar a configuração da precipitação pluvial, demarcando localizações de atenção naquele episódio. E essa configuração e demarcação de localizações pode ser explicada quando analisada de forma integrada com elementos e fatores que compõem e interferem na dinâmica climática. Associado ao uso da escala fina para análise espaço-temporal da precipitação pluvial cabe mencionar que, segundo Longley et al. (2013, p.92), “o nível de detalhe de uma base de dados em SIG, é uma das suas propriedades mais importantes, já que determina tanto o grau de aproximação desta base com o mundo real como a sua complexidade”.

\section{Conclusões e considerações finais}

A análise dos eventos extremos de chuva associados aos episódios de inundação necessita de uma abordagem pautada em escala fina tanto espacial quanto temporal, possibilitando evidenciar sua 
configuração e localização mais acurada. Análises que evidenciam a configuração e localização com alta acurácia proporcionam um auxílio positivo de grande impacto nos resultados da gestão de riscos. Conhecer os lugares de risco e em risco, assim como a dinâmica da configuração desses riscos, é essencial para prevenir e controlar os desastres de origem hidrometeorológica.

Mesmo com apenas dois episódios de exemplificação, o presente trabalho demonstra que a dinâmica climática, em especial o enfoque sobre os sistemas atmosféricos e a direção e velocidade dos ventos, constitui fator de extrema relevância para mapeamento das áreas de inundações. No entanto, o desafio consiste em como considerar esse elemento de ordem qualitativa, em forma de representação quantitativa, por meio de mapeamentos e simulações.

No âmbito de Curitiba e seu aglomerado urbano observou-se que a precipitação pluvial originada com a atuação de uma Mta se desloca de leste para norte, escoando para o oeste e sudoeste. De outra forma, a precipitação pluvial desencadeada pela FF, avança do sul, com direção ao centro-oeste e centro-leste, se deslocando para nordeste, que proporciona sua continuidade no continente e avançando para o Estado de São Paulo, ou sua dissipação no oceano. Essa configuração é resultado direto da condição climática do lugar, e sua relação os fatores geográficos locais e regionais.

Os resultados aqui apresentados permitem concluir que as avaliações realizadas na escala temporal de 24 horas para os dos dados de precipitação pluvial, e com estação dentro do raio de $13,5 \mathrm{~km}$, conforme é recomendado pela Organização Mundial Meteorológica (WMO, 1994), são insuficientes para análise das inundações. Para os dois episódios analisados, que foram desencadeados por Mta e FF, a variação da precipitação pluvial horária entre os 40 e 42 pluviômetros, dentro do período do evento extremo de chuva, foi superior a $100 \%$.

Conclui-se, portanto, que a aplicação da escala fina em estudos climato-geográficos é de alta relev6ancia para o avanço na qualidade, em termos de acurácia, dos resultados das pesquisas. Para a análise das inundações, essa constatação é ainda mais evidente, uma vez que as inundações são fenômenos decorrentes de eventos extremos, que são espacialmente bem localizados e, em sua grande 
maioria de curta duração. Para o emprego da analise de eventos hidrometeorológicos extremos faz-se mister o monitoramento em escala horária e em minutos da precipitação, além de uma boa malha de estações pluviométricas.

\section{Agradecimentos}

Ao CEMADEM por disponibilizar dados de precipitação pluvial dos pluviômetros automáticos, e ao SIMEPAR por disponibilizar dados climáticos da estação automática.

\section{REFERÊNCIAS}

AMARAL, R. do.; RIBEIRO, R. R. Inundação e enchentes. In: TOMINAGA, L. K.; SANTORO, J.; AMARAL, R. do. Desastres naturais: conhecer para prevenir. São Paulo: Instituto Geológico, 2009, p. 39-52.

BANDA B. Forte chuva causa diversos alagamentos em Curitiba e região; veja fotos. Banda B, Curitiba-PR, 2017. Disponível em: http://www.bandab.com.br/geral/forte-chuva-causa-diversos-alagamentos-em-curitiba-e-regiao-fotos-evideo/, acesso em 28 de dezembro de 2017.

BOTELHO, R. G. M. Bacias hidrográficas urbanas. In: GUERRA, A. J. T. (Org.). Geomorfologia urbana. Rio de Janeiro: Bertrand Brasil, 2011, p. 71-115.

CONTI, J.B. Considerações sobre mudanças climáticas globais. SANT'ANNA NETO, J.L. \& ZAVATINI, J.A. Variabilidade e mudanças climáticas: implicações ambientais e socioeconômicas. Maringá: Eduem, 2000.

CUNHA, S. B. Canais fluviais e a questão ambiental. In: CUNHA, S. B.; GUERRA, A. J. T. (Org.). A questão ambiental: diferentes abordagens. 3. ed. Rio de Janeiro: Bertrand Brasil, 2007, p. 219-238.

CUNICO, C. Do risco à adaptação: a identificação da vulnerabilidade socioambiental de Curitiba - PR. 288f. Tese (Doutorado em Geografia) - Setor de Ciências da Terra, Universidade Federal do Paraná, Curitiba, 2013.

DESCHAMPS, M. V. Vulnerabilidade socioambiental na região metropolitana de Curitiba/PR. Tese (Doutorado em Meio Ambiente e Desenvolvimento) - Universidade Federal do Paraná, Curitiba, 2004.

FORTUNATO, R.A. Subsídios à Prevenção e Controle das Inundações Urbanas: Bacia Hidrográfica do Rio Belém Município de Curitiba - PR. 237 f. Dissertação (Mestrado em Construção Civil) - Setor de Tecnologia, Universidade Federal do Paraná, Curitiba, 2006.

GEISSLER, H.J. e LOCH, R.E.M. Análise Histórica das enchentes em Curitiba - PR, Medidas Propostas e consequências observadas. Florianópolis: UFSC, 2004.

GREGORIO, L. T.; SAITO, S. M.; SAUSEN, T. M. Sensoriamento remoto para a gestão de risco de desastres naturais. In: SAUSEN, T. M. \& LACRUZ, M. S. P. Sensoriamento Remoto para desastres. São Paulo: Oficina de Textos, 2015, p. 4367.

ISAAKS, E.H.; SRIVASTAVA, R. M. Applied Geostatisties. New York: Oxford University Press, 1989. 
LOHMANN. M. Regressão logística e redes neurais aplicadas à previsão probabilística de alagamentos no município de Curitiba, PR. 230f. Tese (Doutorado em Geografia) - Programa de Pós-Graduação em Geografia, Universidade Federal do Paraná, Curitiba, 2011.

LONGLEY, P. A; GOODCHILD, M. F.; MAGUIRE, D. J; RHIND, D. W. Sistemas e ciência da informação geográfica. 3. Ed., Porto Alegre: Bookman, 2013.

MARENGO, J. A. Impactos de extremos relacionados com o tempo e o clima - Impactos sociais e econômicos. Boletim do Grupo de Pesquisa em Mudanças Climáticas -GPMC. Instituto Nacional de Pesquisas Espaciais -INPE. Centro de Ciências do Sistema Terrestre -CCST Número 8 - Maio de 2009 - Edição Especial, 2009.

MENDONÇA, F. e DANNI-OLIVEIRA, I. M. Climatologia: noções básicas e climas do Brasil. São Paulo: Contexto, 2007.

MENDONÇA, F.; DESCHAMPS, M.; LIMA, M.D.V.de. A cidade e as mudanças globais: (intensificação?) - Riscos e Vulnerabilidades Socioambientais na RMC - Região Metropolitana de Curitiba/ PR. In: OJIMA, R; MARANDOLA JR, E. Mudanças Climáticas e Cidades: novos e antigos debates na busca da sustentabilidade urbana e social. São Paulo: Blucher Coleção População e Sustentabilidade, 2013, p.129-162.

MENDONÇA F.A. Evènements climatiques extrêmes dans l'Etat du Parana (Brésil): Risques et défis de la gestion publique. In: XXVI Colloque International de l'AIC, 2013, Cotonou - Bénin. Climat, agriculture et ressources en eau: D'hier à demain - Actes du Colloque. Cotonou: Univ. Abomey-Callavi, v. 1., 2013, p. 402-408.

MENDONÇA, F. A.; BUFFON, E. A. M.; GOUDARD, G. l'adaptation urbaine au changement climatique global: les inondations à Curitiba et Pinhais (Brésil) In: XXVIIIe Coloque de l'Associon Internationale de Climatologie. Liège (SartTilman)/Belgique, 2015, p. 200-205.

MENDONÇA, F. A.; BUFFON, E. A. M. Les inondations à Curitiba/Brésil : approche spatiotemporelle fine associée à la dynamique climatique. In: Annales du XXXI Colloque de l'AIC, 2018, Nice - France. Annales du XXXI Colloque de l'Associon Internationale de Climatologie. Nice - France: Univ Nice Sophia Antipollis, 2018. v. 1. p. 32-38.

MONTEIRO, C. A. de F. Análise rítmica em Climatologia - problemas da atualidade climática em São Paulo e achegas para um programa de trabalho. Climatologia vol. 1, São Paulo, n. 1, 1971.

MONTEIRO, C. A. F. Teoria e clima urbano: Um projeto e seus caminhos. In: MONTEIRO, C. A. F. \& MENDONÇA, F.A. Clima Urbano. São Paulo: Contexto, 2003.

RIC MAIS. Chuva deixa ruas alagadas e causa transtornos em vários bairros de Curitiba. Redação Ric Mais, Curitiba-PR, 2016. Disponível em: https://pr.ricmais.com.br/dia-a-dia/noticias/chuva-deixa-ruas-alagadas-e-causa-transtornos-emvarios-bairros-de-curitiba/, acesso em 28 de dezembro de 2017.

ZANELLA, M. E. Inundações urbanas em Curitiba/PR: impactos, riscos e vulnerabilidade socioambiental no bairro Cajuru. 256f. Tese (Doutorado em Meio Ambiente e Desenvolvimento) - Universidade Federal do Paraná, Curitiba, 2006.

World meteorological Organization. Guide to Hydrological Practices, Data Acquisition and Processing, Analysis, forecasting and other Applications. 5 ed. N 168, Geneva: 1994, 259 p. 